Section Editors

David C. Spencer, MD

Steven Karceski, MD

\title{
Are "statins" beneficial or harmful in multiple sclerosis?
}

Christopher Lock, MBBS, PhD
In this issue of Neurology ${ }^{\circledR}$, Dr. Birnbaum and coauthors study whether cholesterol medications called statins are helpful or harmful when combined with common multiple sclerosis (MS) treatments called interferons in patients who have MS. ${ }^{1}$ Interferons are drugs often used for treating MS, and they include interferon beta-1b (Betaseron) and interferon beta-1a (Rebif, Avonex). Statins are drugs given by doctors to lower cholesterol. Statins do more than lower cholesterol (figure). They also affect the body's immune system (the system that helps the body fight infection and sickness) and decrease inflammation. The antiinflammatory effects may partly explain why these medications protect patients against heart attacks and strokes. Some studies have suggested that these effects of statins might help patients with MS. Animals with a disease similar to MS did better when a statin was combined with MS therapy. ${ }^{2}$ Small studies in patients with MS or at risk for developing MS suggested a possible benefit of statins. ${ }^{3}$ Could a benefit of statins when added to interferons be confirmed?

HOW WAS THE STUDY DONE? Dr. Birnbaum and co-authors asked whether a high dose of a statinatorvastatin — can be given safely to MS patients taking an interferon. Twenty-six patients with relapsingremitting MS who were taking interferon beta-1a three times a week entered the study. All patients had to have stable disease activity for 6 months before the study began. The MS patients stayed on interferon, and then started on atorvastatin ( 40 or $80 \mathrm{mg}$ ) or placebo (a "sugar pill") for 6 months. Patients were examined and had pictures of the brain (magnetic resonance images or

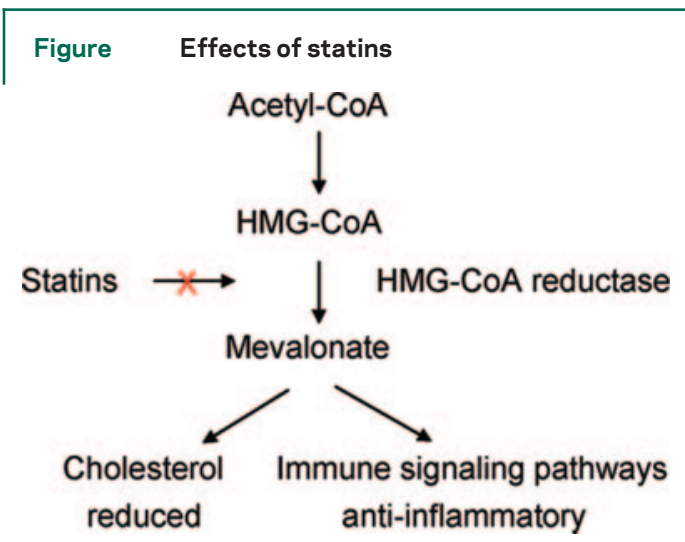

MRIs) done at 0,3 , and 6 months, and after stopping the statin at 9 months. Patients were monitored for signs of increased disease activity on examination or MRI. The study was blinded which means that neither the investigators nor the patients knew which treatment was being given. Blood tests were watched carefully. One patient had abnormal liver tests that may have been related to the interferon or to atorvastatin. There were no other side effects apart from the expected lowering of cholesterol levels in the patients taking atorvastatin.

WHAT WERE THE MAIN FINDINGS? Surprisingly, MS patients treated with atorvastatin seemed to get worse. Ten of the 17 patients who received either $40 \mathrm{mg}$ or $80 \mathrm{mg}$ of atorvastatin had either a relapse or a new lesion on MRI. Only 1 of 9 patients taking placebo had a relapse with active lesions on MRI. In the end, the authors decided that the $40 \mathrm{mg}$ or $80 \mathrm{mg}$ of atorvastatin, taken with interferon, worsened the MS.

WHY IS THIS STUDY IMPORTANT? The study is important for several reasons. Treatments for MS are not completely effective, and combining drugs that work in different ways may improve results. Drugs that can be given by mouth rather than by injection are preferred. Statins have a good safety record, and laboratory studies with animals predict that statins may be helpful to people suffering from MS. However, studies in humans sometimes do not follow the same pattern, or there may be unexpected drug interactions.

\begin{tabular}{|ll|}
\hline Table & $\begin{array}{l}\text { FDA-approved cholesterol-lowering } \\
\text { "statin" drugs }\end{array}$ \\
Chemical name & Trade name \\
Atorvastatin & Lipitor, Caduet (amlodipine/atorvastatin) \\
Fluvastatin & Lescol, Lescol XL \\
Lovastatin & $\begin{array}{l}\text { Altoprev, Advicor (niacin/lovastatin), } \\
\text { Mevacor, generic }\end{array}$ \\
Pravastatin & Pravachol \\
Rosuvastatin & Crestor \\
Simvastatin & $\begin{array}{l}\text { Simcor (niacin/simvastatin), generic, } \\
\text { Vytorin (ezetimibe/simvastatin), Zocor }\end{array}$
\end{tabular}


WHAT IS THE BOTTOM LINE? Today, there is not enough information about the effects of statins on MS to know for certain whether they help or harm. Statins are widely used to treat high cholesterol and are considered safe. Four other studies of statins used with interferons were presented at a European MS meeting last year, and none of these preliminary studies showed a bad effect of taking a statin on MS. Some patients with MS may need to be on a statin to prevent heart disease or stroke. Dr. Birnbaum and co-authors recommend that MS patients taking the combination of a high-dose interferon with a statin should be watched closely, or should take a different statin.

WHAT FUTURE RESEARCH IS NEEDED? Studies using more patients will be needed to know for certain whether there is a harmful interaction between interferons and statins in MS. In small studies like this, there may be random variations between groups, which tend to skew the results. The study did not find that disease activity was worse in MS subjects taking a higher dose ( $80 \mathrm{mg}$ per day) of atorvastatin vs a lower dose (40 mg per day), which might be expected if taking interferon plus atorvastatin was causing worsened disease. Atorvastatin could possibly get in the way of the good effects of interferon, and lower doses of atorvastatin or other statins might not interfere, but this is not known. We hope to have the answer in the next few years.

\section{REFERENCES}

1. Birnbaum G, Cree B, Altafullah I, Zinser M, Reder AT. Combining beta interferon and atorvastatin may increase disease activity in multiple sclerosis. Neurology 2008;71: $1390-1395$.

2. Stuve O, Youssef S, Weber MS, et al. Immunomodulatory synergy by combination of atorvastatin and glatiramer acetate in treatment of CNS autoimmunity. J Clin Invest 2006;116:1037-1044.

3. Vollmer T, Key L, Durkalski V, et al. Oral simvastatin treatment in relapsing-remitting multiple sclerosis. Lancet 2004;363:1607-1608. 
WHAT IS MULTIPLE SCLEROSIS? Multiple sclerosis (MS) is a condition that affects the white matter of the central nervous system (CNS), which includes the brain, spinal cord, and optic nerves. It can be relapsingremitting or progressive. The white matter of the CNS consists of projections of nerve cells or axons covered with a fatty substance termed myelin. Myelin is like the insulation on a wire and the axon is like the core. MS is thought to be an "autoimmune" condition in which the immune system attacks myelin by mistake. While myelin is the main target, MS may affect axons or affect the gray matter of the brain. "Multiple" refers to the involvement of different areas of the CNS at different times, and "sclerosis" refers to the scarring that occurs where the myelin is injured. The damage to myelin can cause slowing or block conduction in the nerve, disturbing the flow of information to and from the brain and spinal cord.

WHAT ARE THE SYMPTOMS OF MS? The symptoms of MS vary from person to person depending on where myelin injury occurs. Symptoms may include changes in vision, numbness, weakness, dizziness, imbalance, difficulty walking, fatigue, and changes in sexual function, bladder and bowel function, and cognition. The course and severity of MS is unpredictable and covers a broad range. Most people with MS have a normal or near-normal life expectancy.

WHO IS LIKELY TO SUFFER FROM MS? About 400,000 people in the United States and 2 million around the world have MS. Most MS begins between 20 and 30 years of age, but MS may affect children or begin in later life. Women are affected about two to three times as often as men are. MS is more frequent in countries further from the equator. MS is not a genetic disease, but having an affected relative increases the risk of developing MS. These observations point to both environmental and genetic factors.

HOW IS MS DIAGNOSED? MS is diagnosed by medical history, neurologic examination, MRI of the brain and spinal cord, and analysis of spinal fluid. Blood tests are used to rule out other conditions that can mimic MS. There is no single laboratory test for MS. To make a diagnosis, there must be evidence of injury to at least two separate areas of the CNS, occurring at different points in time, and other conditions must be ruled out.

WHAT TREATMENTS ARE AVAILABLE FOR MS? There are now six FDA-approved drugs to help MS: beta interferons (Avonex, Betaseron, and Rebif), glatiramer acetate (Copaxone), mitoxantrone (Novantrone), and natalizumab (Tysabri). High-dose corticosteroids are often used to treat flare-ups. Other medications are available to manage symptoms. Physical therapy and rehabilitation can help improve and maintain function.

WHAT ARE THE CURRENT AREAS OF INTEREST IN MS? Among the many areas of investigation, several stand out:

1. Clinically, MS is classified into relapsingremitting, secondary progressive, and primary progressive subtypes. Different MS types may have different causes, and in the future it may be possible that MS will be further divided into different subtypes based on other tests.

2. Biomarkers (blood tests, MRI techniques, or other biomarkers) could help to predict the course of MS and response to treatment.

3. Advances in the understanding of the immunology of MS has brought attention recently to new parts of the immune system that may play an important role in the disease and that may be targets for therapy.

4. There are probably a large number of genes involved in determining whether someone could have MS, and recent family studies have identified several new candidates.

5. Many new drugs are being studied, including several that can be taken by mouth. Combination therapies are being tested. As well as stopping the injury to myelin by damping down the misdirected immune response, a large effort is being made to repair nerves, which holds great promise for the future.

\section{FOR MORE INFORMATION}

National Multiple Sclerosis Society, www.nmss.org National Institute of Neurological Disorders and Stroke, http://www.ninds.nih.gov/disorders/multiple_ sclerosis/ multiple_sclerosis.htm 


\title{
Neurology
}

\author{
Are "statins" beneficial or harmful in multiple sclerosis? \\ Christopher Lock \\ Neurology 2008;71;e54-e56 \\ DOI 10.1212/01.wnl.0000335940.94945.16
}

This information is current as of October 27, 2008

\section{Updated Information \& Services}

\section{References}

Subspecialty Collections

Permissions \& Licensing

Reprints including high resolution figures, can be found at: http://n.neurology.org/content/71/18/e54.full

This article cites 3 articles, 1 of which you can access for free at: http://n.neurology.org/content/71/18/e54.full\#ref-list-1

This article, along with others on similar topics, appears in the following collection(s):

Multiple sclerosis

http://n.neurology.org/cgi/collection/multiple_sclerosis

Information about reproducing this article in parts (figures,tables) or in its entirety can be found online at:

http://www.neurology.org/about/about_the_journal\#permissions

Information about ordering reprints can be found online: http://n.neurology.org/subscribers/advertise

Neurology ${ }^{\circledR}$ is the official journal of the American Academy of Neurology. Published continuously since 1951, it is now a weekly with 48 issues per year. Copyright. All rights reserved. Print ISSN: 0028-3878. Online ISSN: 1526-632X.

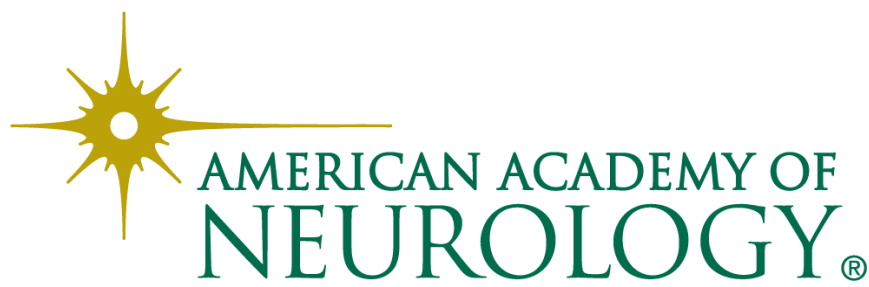

